\title{
Nursing expertise: a course of ambiguity and evolution in a concept
}

\section{ABSTRACT}

In this paper we clarify and describe the nature of nursing expertise and provide a framework to guide its identification and further development. To have utility and rigor, concept-driven research and theories of practice require underlying concepts that are robust, valid and reliable. Advancing understanding of a concept requires careful attention to explicating its' knowledge, metaphors and conceptual meaning. Examining the concepts and metaphors of nursing expertise, and how they have been interpreted into the nursing discourse, we aimed to synthesise definitions; similarities between concepts; and elicit the defining characteristics and properties of nursing expertise. In clarifying the concept, we sought to move beyond the ambiguity that currently surrounds expertise in nursing and unravel to make explicit the characteristics of nursing expertise from published peerreviewed studies and structured literature synthesis. Findings indicate a lack of clarity surrounding the use of the term expertise. Traditional reliance upon intuition as a way of explaining expert performance is slowly evolving. Emerging from the analysis is a picture of expertise as the relationship between networks of contextual reasoning, understanding, and practice. Striking absences in the discourse include limited explication of ethical reasoning and theorising a broader interpretation of expertise reflective of contemporary forms of nursing.

Keywords: concept analysis, nursing workforce, nursing, expertise, professional competence, expert practice. 
For many years nursing has been largely framed as a practice discipline. The concept of nursing expertise is widely, and at times, uncritically employed in nursing and healthcare discourses. The extent of material published on the topic suggests substantial and ongoing attempts to define and understand the nature of expertise. Notwithstanding Benner's seminal work (Benner 1984), which attempted to articulate how expertise develops in nursing, there remains little consensus on the specific characteristics of nursing expertise, or how these may be identified or developed. Even though expertise is employed as the basis for differentiating various nursing roles and titles, the interpretation and application of expertise is variable and lacks clarity (Currie and Watterson 2009).

Whilst nurses and patients can readily recognise expertise when they see it, the discourses surrounding expertise are less clear, and the issue remains one of establishing a clearer definition and specification. Without clear definition, expertise can be claimed perhaps inappropriately, or it risks being assumed without any specific rationale. This lack of clarity has meant that nurse clinicians, managers, academics and researchers have experienced difficulty focusing efforts to recognise and evidence expertise.

There is also considerable discrepancy in the workforce with regard to who is considered an expert, or the criteria through which expertise is conferred. To date the main focus has been on clinical expertise, with non-clinical elements of nursing expertise not being scrutinised or elucidated. However, in the last few decades, in addition to developing as a practice discipline, nursing has developed as an area of research and scholarship. This raises the need to theorise more clearly what we mean when we talk about expertise. One of the major difficulties with the notion of expertise is defining the concept. Expertise remains a nebulous concept which is variously defined, leading to confusion about who can claim expertise or whether there are specific capabilities, capacities or context required of those claiming expertise. Given the extent of the discourse on nursing expertise, it is timely to establish whether the dimensions of expertise can be clarified from the extant body literature on the topic. Here we report a concept analysis undertaken to clarify and describe the 
nature of nursing expertise and provide a framework to guide the identification of expertise in nursing.

Concept analysis is a recognised methodology for research and theory building; it is also a useful strategy for understanding concepts that 'represent complexities of actions' (Morse, Mitcham, et al. 1996, 385) that are difficult, but not impossible to identify and assess. Meleis (1991) noted that nursing is represented through a multiplicity of concepts, and these concepts form the building blocks of nursing practice, theory and research. As concepts are inextricably linked with knowledge and practice, understanding the nature of concepts, such as expertise, and the role such concepts play in knowledge development is a concern for practitioners, educators, scholars and researchers (Rodgers 2000a). In mapping the concept of nursing expertise from the substantive nursing literature, we sought to derive commonalities and elicit new insights. Moreover, as 'concepts are about ontology' (Goertz 2006 27), we sought to move beyond simply defining the concept of expertise by summarising the literature, towards a more critical reflection to inform theoretical and practical development in the field.

\section{THE CHARACTERISTICS OF NURSING EXPERTISE}

Debate about the nature of expertise is not new to nursing. For more than three decades scholars have sought to understand the nature of expert reasoning, and the performance characteristics that distinguish expert from novice. Two competing epistemological interpretations of expertise have dominated thought on this topic. Empiricist notions of expertise have privileged fact and scientific reasoning. From this perspective, it has been argued that expertise develops through the mastery of rules and knowledge. The second interpretation, informed through phenomenology, interprets expertise as an embodied form of social learning (Dreyfus and Dreyfus 1986) that is deeply tacit and context-laden. The evolution of thinking between these two strands of knowledge development has provided insight into the nature of propositional knowledge, ("knowing what") and situational knowledge ("knowing how"). Chin and Kramer (2011) noted that these two forms of reasoning 
create different knowledge products. The empiricist seeks to describe, explain and predict, whereas the clinician derives context specific information that allows them to modify and extend their repertoire of tacit knowledge and formulate patterns of knowing (Jacobs-Kramer and Chin 1988). Epistemological questions about knowledge and the nature of practice have been informed by a number of influential models about knowing in nursing, and the nature and development of expertise (Sandelowski 1994, Chinn and Kramer 2013, Carper 1978, Benner 1994). This trend in nursing reflected a similar trend occurring in education, the humanities and social sciences (Ericsson and Smith 1991, Hofer and Pintrich 1997).

Two influential theorists on knowledge development in nursing are Carper and Benner (Carper 1978, Carper 1992, Carper 1979, Benner, Tanner, and Chesla 2009, Benner 2001). Carper $(1978,17)$ proposed a schema of four patterns of knowing that are said to be employed by nurses (empirical, ethical, aesthetic and personal). Through aesthetic knowing, Carper theorised that nurses draw together dispersed details about a particular situation and synthesised this into a whole. Reflecting the overarching narrative of privileging lived experience, Carper proposed that aesthetic, personal and ethical knowing are richer and more authentic forms of knowing than empirical knowing. A decade later, Benner's influential work focused attention upon understanding the changing nature of performance between novice and expert nursing (Benner 1984). In her model, Benner theorised individual's progress from the concrete thinking of the novice, to the more abstract forms of embodied reasoning and practice of the expert (Lyneham, Parkinson, and Denholm 2008). In Benner's framework, the ability to intuitively make judgements is said to characterise the expert nurse. It is argued that the expert no longer relies upon step-by-step deductive reasoning to connect learnt knowledge and skill to a situation and make appropriate decisions (Benner et al. 2008). Instead, influenced by Polanyi (1997) and Merleau-Ponty (1964), (From Novice to Expert) Benner (1978) asserted that an expert draws upon tacit embodied and somatic knowledge in their decision making processes. In the nursing vernacular, it is commonly held that the tacit or intuitive knowledge which characterises expertise is opaque, undefinable, and intuitive and not easily 
captured or described (King and Clark 2002, Lyneham, Parkinson, and Denholm 2008, Christensen and Hewitt-Taylor 2006). Accordingly an expert is viewed as someone who "knows more than they tell' (Kinchin and Cabot 2008,93) and who through tacit knowledge, follows intuition. Although there is no universal agreed definition of intuition, there is broad consensus in the nursing literature on its contextual meaning.

\section{Expertise as tacit and opaque}

Inspired by philosophers such as Wittgenstein (Baker, Hacker, and Wittgenstein 1983), Heidegger (Heidegger, Gray, and Wieck 1968), Merlau-Ponty and Polyani (Merleau-Ponty 1964, Merleau-Ponty and Smith 1996, Polanyi 1997, 2012), nurse researchers and scholars have theorised expertise as a form of embodied immersion and tacit knowledge, which is derived from a deep understanding of socially constructed contexts and events. Intuition has been conceived as the process of employing context and experience as the vehicle through which reasoning and decision making occurs. This tacit embodied knowledge and reasoning is difficult to surface in language as it is connected to somatic responses, rather than purely cognitive thought processes (Benner 1984).

The widely held notion in the nursing literature that expertise is tacit or opaque (Meerabeau 1992, Herbig, Büssing, and Ewert 2001), and therefore unable to be described in language, risks limiting practical progress about the nature of expertise in nursing (Fealy and McNamara 2015). It also limits discourse and reflective dialogue on the nature of expertise (Reyes-Galindo and Duarte 2015). An alternative view is to accept that there are individual variations in tacit knowledge, but there is the possibility of 'similar tacit knowledge among individuals sharing a skill, practice, language, or tradition' (Nikkel 2014,33). It is also feasible to understand the process through which expertise develops and operates without necessarily making explicit the finer detail of the knowledge held by experts. Thus there are grounds for explicitly describing the nature of expertise beyond broad brush descriptions. Expertise may be nothing more than a high level of integrative 
performance demonstrated by individuals 'who have a well organised knowledge structure in the particular area of knowledge, and also a strong commitment to persist in finding new meaning' (Novak and Cañas 2008,10).

\section{The importance of specifying the nature of nursing expertise}

Although a large body of research and scholarship has been undertaken on the topic of expertise in nursing, after thirty years there is little consensus on the nature of the phenomenon. There is even less consensus on how it might be recognised. Without the capacity to more clearly specify expertise, its application is open to wide interpretation and the practical and theoretical utility of the concept is limited. The specification and clear description of the tacit dimensions of expertise is overdue. In this analysis we were interested to employ concept analysis as a bridge between the polarised interpretations of expertise. Through examining the concepts and metaphors of nursing expertise, and how they have been interpreted into the nursing discourse by nurse researchers, practitioners and scholars, we sought to synthesise definitions of expertise; similarities between the concepts described; the attributes of expertise; and its antecedents.

\section{METHOD}

For this analysis, as there was a substantial body of data published on the topic, we aimed to abstract from published sources the characteristics of nursing expertise. The approach adopted was one of concept clarification and unravelling to make explicit the characteristics of nursing expertise (Morse, Hupcey, et al. 1996). Employing secondary peer-reviewed sources, the critical elements of what has been described about nursing expertise and the pattern of usage was analysed (Risjord and Risjord 2009). This form of secondary data analysis is an established method of deriving definitional clarity and constructing consensus on the characteristics of a phenomenon. Initially, relevant research and substantive papers on the concept of nursing expertise were identified. A databased approach was adopted to locate relevant peer-reviewed papers. The second step involved distinguishing and defining the concepts to be included in the analysis. Thirdly, concepts were 
broken down into their parts from which a concept map could be constructed. Following Rodgers and Knafl (2000) the contextual information, similarity between concepts, and the attributes of expertise and their application are described.

Rodgers framework for concept analysis was adopted to guide the analysis and interpretation (Rodgers 1989) as the evolutionary approach focuses attention upon concept development and implications for further theoretical and conceptual development (Rodgers 2000a). Rodgers (2000a) method of concept analysis has been termed evolutionary and centres on the idea that concepts evolve in a cycle of phases: significance, use and application. Rodgers subscribes to the view that concepts are dynamic, 'fuzzy', context dependent and serve a pragmatic utility rather than an innate 'truth' (Rodgers, 2000a). Concept development is evolutionary, and continues over time within a particular context, which may be disciplinary, cultural or theoretical. (Weaver and Mitcham, 2008:191)

\section{Concept definition}

For the purpose of concept analysis it is important to ensure definitional clarity and differentiate between similar or closely aligned concepts. For the purpose of this paper, an expert is defined as an individual who possesses tacit knowledge and mastery of a domain (Collins et al. 2006).

A concept closely aligned to expertise in the nursing literature is that of competence. The notion of competence suggests the ability to satisfactorily perform a range of skills required in routine situations, and to act efficiently and safely. Beginning level competence is required for registration, and many jurisdictions require an annual re-statement of continued competence as a pre-requisite for ongoing registration as a nurse. Competence is widely used to determine the knowledge and skills required to solve familiar problems and ensure adequate and safe levels of care. Thus, competence is a form of technical expertise which relates to mastery, and individuals 
can become expert with sufficient practice. This differentiation is used widely across the professions (Ge'linas-Phaneuf and Del Maestro 2013). This is in contrast to expertise, which is a skilled form of adaptive mastery which enables individuals to solve novel and unfamiliar problems through higherorder reasoning and performance (Ge'linas-Phaneuf and Del Maestro 2013). A nurse with extensive years of experience may demonstrate technical capability across a broad range of skills, yet this nurse may not meet the criteria for expertise. As years in practice does not automatically align with expertise.

\section{Data sources and search strategy}

A computerised search of the bibliographic full text databases CINAHL within EBSCO and PubMed (nursing journals) was conducted by the first author. Initially MESH and subject terms for expertise were identified and key search terms and subject headings used were expertise, professional competence, technical expertise and clinical competence. These were combined with nurs* and limiters applied including full text peer-reviewed journals and papers available in English for the period 1990 - September 2015 to capture the body of empirical work produced subsequent to Benner's foundational treatise. Title and abstract searches of the manuscripts identified from the search $(n=1324)$ were undertaken to screen manuscripts. Figure 1 presents a PRISMA flowchart (Liberati et al. 2009) for the search process. The inclusion criteria included primary studies of nursing expertise and structured or systematic literature reviews on the topic (Hupcey and Penrod 2005). Following abstract review, manuscripts not retained largely focused upon competence, curriculum development or nurse education, examined influencing factors for the development of expertise, loss of expertise, or the development of specific clinical skills. Editorial or commentaries were also excluded, resulting in 104 manuscripts retained from the initial search. Following full paper review the pool of manuscripts was reduced further and an additional two papers were identified from citation screening of retained manuscripts. The final number of manuscript retained for analysis was 16. Table 1 summarises detail on these manuscripts. 


\section{INSERT FIGURE 1 HERE}

\section{INSERT TABLE 1 ABOUT HERE}

\section{Quality review}

As we aimed to examine substantive studies of nursing expertise, and no specific criteria have been developed for quality review in concept analysis, we employed a set of modified criteria from systematic review appraisal tools (CASP) to review the quality of studies (Critical Appraisal Skills Programme (CASP) 2014). The criteria employed to assess the quality of retained papers contained five general criteria that were applied to each study, along with five additional criteria specific to qualitative and quantitative designs and reviews. Mixed methods studies were scored against the 15 criteria and the score averaged to provide a comparative score out of 10 . Quality review was conducted by two of the authors. One paper was excluded from the review as insufficient information was provided in the paper to perform the review, bringing the total number of manuscripts included in the final analysis to 15 . Table two summarises the quality review criteria and the results of quality analysis for the studies employed in the final content analysis. The majority of studies included were qualitative designs, and most of these were of high quality. All quantitative studies included in the review were of a high quality. Two reviews and one qualitative study score below 3 .

\section{INSERT TABLE 2 ABOUT HERE}

\section{Analysis}

Initially each paper retained was read by two of the authors. Relevant findings that related to descriptions of the characteristics of nursing expertise were extracted and compiled into a word file. Through a process of inductive content analysis these textual descriptions of the characteristics of expert practice were assigned codes. Through an iterative process of condensing and clustering, codes were refined into categories based on similarities (Elo and Kyngäs 2008). This process of 
refinement of coded text into categories, and then broader themes with constituent sub-categories, allowed for the concept of expert practice to emerge. The process of clustering and refinement was jointly reviewed and discussed by the entire team, and differences reconciled. The final themes derived from the analysis were: broad or expert knowledge, experience and skills; contextual sensitivity; cognitive discrimination; anticipatory perception; rapid and non-linear reasoning in complex situations; integrative reasoning; saliency and confident performance; leading and influencing; and, catalytic action.

\section{FINDINGS}

\section{Defining expertise}

The term expertise was used to refer to the attributes required of nurses who practice beyond the level of the competent or proficient nurse. An expert was defined as possessing 'attributes that make their practice superior' (Bonner 2003,124) and one who is able to practice holistically rather than conducting 'a series of tasks proficiently' (Christensen and Hewitt-Taylor 2006,1532). Expertise was also defined in terms of performance and as a 'hybrid of practical and theoretical knowledge' (McHugh and Lake 2010,276). No studies reviewed employed specific tools to measure expertise and a number of studies did not define expertise (Conway 1998, Hardy, Titchen, and Manley 2007). The majority explored expertise at the level of the individual nurse. Expertise was examined through self-report of expertise, or through nomination by others.

Both individual characteristics and the practice environment are described as central to the development and exercise of expertise. Theory and knowledge are foundational components of expertise, but expertise does not exist without embodied or context sensitive knowledge, reasoning and performance. It is proposed that theory and knowledge provide a basis that is refined in practice (McHugh and Lake 2010). While experience is central to the development of expertise, time in practice and reflexivity allow the development of embodied knowledge, skills and practice that are fundamental to expert practice. 
Intuition remains a central construct in the explanation of expertise. An embodied understanding of performance is described as the cornerstone of expert knowledge and skill. Knowledge and skills employed by the expert reflect an embodied understanding of the practice context and situation. Understanding practice shapes and organises knowledge.

Expertise is also positioned as a goal to influence the quality of care (McHugh and Lake 2010) and employed as a concept to define clinical ladders for the purpose of recognising and rewarding expert practice (Brykczynski 1998). Concern is also expressed for expertise being a costly resource that requires clarity (Christensen and Hewitt-Taylor 2006) and is necessary for appropriately rewarding expertise (Brykczynski 1998).

\section{Similarities between concepts}

Following the work of Benner and colleagues (Benner 2001, Benner, Tanner, and Chesla 2009) that provided rich narrative accounts of each stage of nursing expertise interpreted through the Dreyfus model, the body of work reviewed in our analysis reflects the continuation of this tradition. Table 3 summarises the theoretical foundations employed to inform each of the papers reviewed. The majority of studies providing detail on the underpinning theoretical framework employed, and cited Benner's model of novice to expert.

\section{INSERT TABLE 3 ABOUT HERE}

To further highlight the similarities in concepts between the papers reviewed, we have provided a summary of the primary domains, constitutive constructs, and indicators identified from the comparative analysis in Table 4. The coding and analysis undertaken allowed for differentiation between constructs and the distillation of similarities. To highlight similarities in how the construct of expertise has been conceptualised in these studies, the frequency effect size (Sandelowski, Barroso, and Voils 2007) was calculated by dividing the number of times the constructs were reported in the pool of studies reviewed. Effect sizes above 15 suggest significant consensus exists 
on the construct within the body of work reviewed (Sandelowski, Barroso, and Voils 2007). Constructs with strong levels of consensus (above 40\%) were: theory and knowledge; context relevant experience; sensitivity to patient context; and recognises what is salient in a situation; seamless performance, awareness or placement of self in situation.

\section{INSERT TABLE 4 ABOUT HERE}

\section{Attributes of expertise}

The attributes of the concept provide an expanded interpretation of a construct under definition (Morse, Hupcey, et al. 1996). In defining the attributes of expertise, the taxonomy derived highlights the embedded and contextual nature of expertise; it also focuses attention upon the forms of reasoning employed and differentiates the constituent components of saliency, discrimination, perception and integration which form part of the reasoning process. The detailed analysis illuminates contextualisation and perceptual and connected responsiveness which often viewed as opaque and tacit. A feature of expertise is the capacity to recognise subtle features of context, and through an adaptive process, integrate knowledge and situated context into performance.

\section{Antecedents of expertise}

Antecedents are the contextual basis and conditions required for the concept to materialise (Knafl and Deatrick 2000). From our analysis, it can be postulated that expertise is a function of: time, experience, and theory/knowledge, which are situated in a context that enables and sustains perception, contextual sensitivity, discrimination, advanced reasoning and complex performance. Only a small number of papers specifically identified time as an antecedent, although experience, which incorporates an assumption time, was identified more commonly. The concept of time has also been affirmed in studies of medicine which indicate decay of medical performance is a function of time, experience and taught knowledge (Ericsson 2004). Although time and knowledge are 
identified as antecedents, along with exposure to a conducive environment, the development of expertise is likely to be variable.

The taxonomy illustrates how aspects of expertise that are often framed as intuition can be understood as the relationship between theory and knowledge and 'networks of understanding' (Kinchin and Lyndon 2010, 153). Kinchin, Cabot, and Hay (2008) use the analogy of chains and networks to map the dimensions of expertise. Applying this concept to our analysis (see Figure 2), the foundation of expertise are chains of learnt knowledge, technical skill or accumulated experiential knowledge. The domain of broad or expert knowledge, experience and skills provide a catalogue of chains or sequences of "how" knowledge about specific events or situations. These chains of knowledge or skill are in themselves insufficient to characterise expertise. For expertise to be evidenced these chains of knowledge are operationalised through networks of understanding. It is these networks of understanding that have often been labelled intuition in the nursing discourses. The domains of contextual sensitivity, discrimination, and anticipatory perception provide "when" and "why" knowledge that allows for integrated understanding about what is relevant in the situation. Whereas the domains of rapid and non-linear reasoning and integrative reasoning depict the process through which these chains and networks are drawn upon in reasoning and decision making processes. Depending on the nature of the expertise the chains of knowledge will vary, whereas the capacity to utilise networks of understanding in a proficient, rapid and context sensitive manner are the hallmark features of expertise.

\section{INSERT FIGURE 2 HERE}

\section{DISCUSSION}

We have systematically considered how the interpretation of the characteristics of expertise have been represented in the nursing literature. This paper is based on literature derived from the English language peer reviewed primary research and structured reviews, therefore insights derived from non-peer reviewed literature and non-English language literature are not included. By mapping 
the concept, our analysis has revealed the complementary knowledge structures and integrative forms of understanding that exemplify nursing expertise.

It is evident that expertise does not solely arise from content knowledge, or any one of the knowledge structures or reasoning or performance components detailed in our interpretation. A hallmark of expertise is the ease and speed of reasoning and performative interaction between these knowledge structures and networks of understanding. For more than two decades theorising about nursing expertise has focused upon experiential interpretations of expertise and how it emerges from practice, giving rise to the view that expertise is a nebulous and tacit concept (Butler et al. 2011). Notwithstanding Benner's seminal work (Benner 2001, Benner, Tanner, and Chesla 2009), which attempts to articulate how expertise develops in nursing, there seems to be an assumption that the development is automatic, and aligned with exposure to the clinical environment. In developing a detailed interpretation of expertise, we have uncovered and explained what are often considered intuitive or tacit phenomenon.

In the period following Benner and Carper, nursing has continued to develop as an area of research and scholarship, as well as a practice discipline. It is striking that, more than twenty years of nursing research and academic practice have not led to a broadening of interpretations about the nature and characteristics of nursing expertise. As evidenced by our analysis, the assumption of scholarship on the topic, is that expertise is synonymous with clinical expert. Little attention has been given to theorising a broader interpretation that reflects contemporary forms of nursing. Extending thinking and theorising about nursing expertise across the broader discipline would illuminate aspects of expertise absent from current interpretations. For example, knowledge creation is absent from the nursing discourse on expertise. We suggest the time has come to move beyond the limited interpretation of expertise as only evidenced in clinical practice, and instead, begin to build bridges between the shared and unique components of expertise across nursing fields towards an interpretation that provides insight into to the full scope of nursing expertise. Developing an integrated or more complete interpretation of expertise would illuminate how 
practice knowledge informs the development of other forms of knowledge, and vice versa. It would also offer the opportunity to clarify the place of practice knowledge as the foundation upon which other forms of expertise are developed. Boyer's (1991) landmark work called for an integrated interpretation of scholarship. In a similar vein, we suggest that nursing expertise might usefully be conceptualised as having distinct but overlapping domains.

A further striking aspect of the findings from our analysis is that ethical and aesthetic knowing are not features of the constructs identified from the literature reviewed. Informed largely through Benner's work, the literature is replete with descriptions of expertise as embodied knowledge. Polyani (Polanyi 1997, 2012) and Merleau-Ponty (Merleau-Ponty 1964, Merleau-Ponty and Smith 1996) hypothesised several forms of intuitive knowledge. Embodied knowledge, which is the main focus of much nursing literature is a form of somatic or embodied knowledge. Mapping the constructs identified in our analysis to Carper's (1978) four forms of knowing indicates attention has primarily been given to identifying empirical and aesthetic forms of knowing. Of note, what remains largely absent from the recent nursing discourses on expertise is an understanding of moral expertise and how expert nurses foreground within their decisions and actions consideration of morally, what ought to occur in a given situation. Given the ethical complexity of nursing work, consideration to the moral aspects of nursing expertise warrant more detailed explication. Similarly, Carper's (1978) notion of personal knowing has been given little consideration.

It is evident that issues remain with definitional clarity around aspects of nursing experts. This is problematic as it remains unclear who can claim expertise. For example, an academic with extensive theoretical knowledge in a particular filed may claim expertise in a field of nursing. Applying the interpretation we have distilled from the literature, without having also spent time working in the field to develop the requisite networks of knowledge that allow for contextual sensitivity and discrimination, content knowledge is insufficient to claim expertise. Similarly an academic who has spent time away from clinical practice is likely to have expertise decay, and the capacity to claim expertise would diminish over time. The framework we have distilled also provides 
answers to the question of whether time in a field is sufficient on its own to claim expertise. Clearly, time is only a small aspect of what contributes to expertise, and on its own is an insufficient criteria. The analysis can also usefully be applied to establishing benchmarks for entry into advanced practice nursing roles such as Nurse Practitioner. With students being admitted to nurse practitioner programs with only one year of postgraduate experience, this raises the question of whether graduates from such programs can legitimately claim the title of expert.

Finally, specifying the characteristics of expertise is an important consideration for workforce planning, as it is widely recognised that the quality of nursing care provided and patient outcomes are linked to nursing workforce characteristics. To date this work has taken limited approached to the exploration of expertise and the link to patient outcomes (for example, Duffield et al. 2009). Investigators have also begun to explore nursing capital and the nature of theoretical and practical capital in the workforce and its influence on the delivery of care (Covell and Sidani 2013). For nurses, questions arise, particularly in the current environment where we see expertise sometimes claimed on the basis of sociologically-informed research into a particular area; rather than any clinical exposure, and in the absence of advanced clinical skill or reasoning and performance. A clearer understanding of the characteristics of expertise in the context of nursing would bring some clarity to this area.

\section{CONCLUSIONS}

The absence of a language of expertise, or tools that can support nurses to describe expert knowledge and thereby make explicit what is held as tacit, remains a challenge for this body of discourse. Although Dreyfus holds that experts are typically unable to pass on all that they know through discourse, shared language is held as a hallmark of expertise. In distilling the framework offered from our analysis, we have gone some way to providing a clearer language and conceptualisation of nursing expertise. The absence of attention to moral aspects of expertise is a striking deficiency in nursing research and scholarship. Similarly, after more than thirty years of 
attention to the nature of nursing expertise, the absence of conceptualisation beyond notions of clinical expert warrants consideration. The evolution of a partial and limited understanding of the concept of nursing expertise risks being out of step with the contemporary realities of the nursing workforce and the diversification of nursing roles. In re-thinking the concept of nursing expertise, we put forward a framework that extends thinking about the concept and invites re-consideration of some of the taken-for-granted tenets of this discourse. 


\section{REFERENCES}

Baker, G. P. and Hacker, P. M. S. (eds) (2005) Frontmatter, in Wittgenstein: Understanding and Meaning, Volume 1 of An Analytical Commentary on the Philosophical Investigations: Part I: Essays, Blackwell Publishing, Malden, MA, USA. doi: 10.1002/9780470752807.fmatter

Benner P. 1984. From novice to expert. Menlo Park, CA: Addison-Wesley.

Benner P, M Sutphen, V Leonard-Khan and L Day. 2008. Formation and Everyday Ethical Comportment. American Journal of Critical Care 17:473-476

Benner P. 1994. Interpretive phenomenology: Embodiment, caring, and ethics in health and illness. Thousand Oaks, CA: Sage.

Benner PE. 2001. From novice to expert: Excellence and power in clinical nursing practice. New Jersey. Prentic Hall.

Benner PE, CA Tanner, and CA Chesla. 2009. Expertise in nursing practice: Caring, clinical judgment, and ethics: New Yor, NY. Springer Publishing Company.

Bobay K, DL Gentile, and ME Hagle. 2009. The relationship of nurses' professional characteristics to levels of clinical nursing expertise. Applied Nursing Research 22 (1):48-53.

Bonner A. 2003. Recognition of expertise: An important concept in the acquisition of nephrology nursing expertise. Nursing and Health Sciences 5:123-131.

Boyer EL. 1991. The scholarship of teaching from: Scholarship reconsidered: Priorities of the professoriate. College Teaching 39 (1):11-13.

Brykczynski KA. 1998. Clinical exemplars describing expert staff nursing practice. Journal of Nursing Management 6:351-359.

Butler M, R Collins, J Drennan, P Halligan, DP O'Mathúna, TJ Schultz, A Sheridan and E Vilis. 2011. Hospital nurse staffing: models and patient and staff-related outcomes. Cochrane Database of Systematic Reviews 7 (Art. No.: CD007019). doi: 10.1002/14651858.CD007019.pub2. 
Carper BA. 1992. Philosophical inquiry in nursing: An application. Philosophic Inquiry in Nursing 7180.

Carper BA. 1978. Fundamental patterns of knowing in nursing. Advances in Nursing Science 1 (1):1324.

Carper BA. 1979. The ethics of caring. Advances in Nursing Science 1 (3):11-20.

Chin PG and MK Kramer. 2011. Confirmation and validation of emperic knowledge using research. In Integrated Theory and Knowledge Development in Nursing, eds PG Chin and MK Kramer, 206-227. St Louis, MO: Elsevier, Mosby.

Chinn PL and MK Kramer. 2013. Integrated theory \& knowledge development in nursing: St Lois MO: Elsevier Health Sciences.

Christensen $\mathrm{M}$ and J Hewitt-Taylor. 2006. From expert to tasks, expert nursing practice redefined? Journal of Clinical Nursing 15 (12):1531-1539.

Collins H, R Evans, R Ribeiro and M Hall. 2006. Experiments with interactional expertise. Studies in History and Philosophy of Science Part A 37 (4):656-674.

Conway JE. 1998. Evolution of the species 'expert nurse'. an examination of the practical knowledge held by expert nurses. Journal of Clinical Nursing 7:75-82.

Covell CL and S Sidani. 2013. Nursing intellectual capital theory: operationalization and empirical validation of concepts. Journal of Advanced Nursing 69 (8):1785-1796.

Critical Appraisal Skills Programme (CASP). 2014. CASP Checklists. Oxford: CASP. http://www.caspuk.net/\#!untitled/cd2g (accessed 6 November 2015).

Currie $L$ and $L$ Watterson. 2009. Investigating the role and impact of expert nurses. British Journal of Nursing $18(13): 816-824$.

Cutcliffe JR. 1997. The nature of expert psychiatric nurse practice: a grounded theory study. Journal of Clinical Nursing 6 (4):325-332. 
Dreyfus HL and SE Dreyfus. 1986. From Socrates to Expert Systems: The Limits of Calculative Rationality. In Philosophy and Technology II, Volume 90 of the series Boston Studies in the Philosophy of Science, edited by C. Mitcham and A. Huning. Netherlands: Springer.

Duffield CM, MA Roche, LL O'Brien-Pallas, DK Diers, C Aisbett and K Aisbett. 2009. Nursing workload and staffing: Impact on patients and staff. www.health.act.gov.au.

Elo S, and H Kyngäs. 2008. The qualitative content analysis process. Journal of Advanced Nursing 62 (1):107-115.

Ericsson KA and J Smith. 1991. Toward a general theory of expertise: Prospects and limits. Cambridge: Cambridge University Press.

Ericsson KA. 2004. Deliberate practice and the acquisition and maintenance of expert performance in medicine and related domains. Academic Medicine 79 (10):S70-81.

Fealy GM and MS McNamara. 2015. Transitions and tensions: the discipline of nursing in an interdisciplinary context. Journal of Nursing Management 23 (1):1-3.

Ge'linas-Phaneuf N, and RF Del Maestro. 2013. Surgical expertise in neurosurgery: integrating theory into practice. Nuerosurgery 73 (4): S30-s38.

Goertz G. 2000. Social science concepts: a user's guide. Princeton, New Jersey, Princeton University Press.

Hardy S, A Titchen and K Manley. 2007. Patient narratives in the investigation and development of nursing practice expertise: a potential for transformation. Nursing Inquiry 14:80-88.

Hardy S, R Garbett, A Titchen and K Manley. 2002. Exploring nursing expertise: nurses talk nursing. Nursing Inquiry 9 (3):196-202.

Heidegger M,. 1968. What is called thinking? (trans FD Wieck and JG Gray) Vol. 8: New York: Harper \& Row.

Herbig B, A Büssing, and T Ewert. 2001. The role of tacit knowledge in the work context of nursing. Journal of Advanced Nursing 34 (5):687-695. 
Hofer BK and PR Pintrich. 1997. The development of epistemological theories: Beliefs about knowledge and knowing and their relation to learning. Review of Educational Research 67 (1):88-140.

Hupcey JE and J Penrod. 2005. Concept analysis: examining the state of the science. Research and Theory for Nursing Practice: An International Journal 19 (2):197-208.

Jacobs-Kramer MK and P Chin. 1988. Perspectives on knowing: a model of nursing knowledge. Scholarly Inquiry for Nursing Practice: An International Journal 2 (2):129-139.

Johnson ME and PM Hauser. 2001. The practices of expert psychiatric nurses: accompanying the patient to a calmer personal space. Issues in Mental Health Nursing 22 (7):651-668.

Johnston B and LN Smith. 2006. Nurses' and patients' perceptions of expert palliative nursing care. Journal of Advanced Nursing 54 (6):700-709.

Kinchin IM, LB Cabot and DB Hay. 2008. Using concept mapping to locate the tacit dimension of clinical expertise: towards a theoretical framework to support critical reflection on teaching. Learning in Health and Social Care 7 (2):93-104.

Kinchin IM and C Lyndon. 2010. Reconsidering dimesions of epxertise: from linear stages towards dual processing. London Review of Education 8 (2):153-166.

King, L and JM Clark. 2002. Intuition and the development of expertise in surgical ward and intensive care nurses. Journal of Advanced Nursing 37 (4):322-329.

Knafl, KA and JA Deatrick. 2000. Knowledge synthesis and concept development in nursing. In B. Rodgers and Knafl, K.A. (Eds.) Concept development in nursing: Foundations, techniques, and applications. Philadelphia: Saunders. 39-54.

Liberati A, DG Altman, J Tetzlaff, C Mulrow, PC Gøtzsche, JPA loannidis, M Clarke, PJ Devereaux, J Kleijnen and D Moher. 2009. The PRISMA statement for reporting systematic reviews and meta-analyses of studies that evaluate health care interventions: explanation and elaboration. Annals of Internal Medicine 151(4):W-65-W-94. 
Lyneham J, C Parkinson and C Denholm. 2008. Explicating Benner's concept of expert practice: intuition in emergency nursing. Journal of Advanced Nursing 64 (4):380-387.

McHugh MD and ET Lake. 2010. Understanding clinical expertise: nurse education, experience, and the hospital context. Research in Nursing \& Health 33 (4):276-287.

Meerabeau L. 1992. Tacit nursing knowledge: an untapped resource or a methodological headache? Journal of Advanced Nursing 17 (1):108-112.

Merleau-Ponty M. 1964. Sense and non-sense: Chicago, Illinois: Northwestern University Press.

Merleau-Ponty M and C Smith. 1996. Phenomenology of perception: Motilal Banarsidass Publishe.

Morrison SM and L Symes. 2011. An integrative review of expert nursing practice. Journal of Nursing Scholarship 43 (2):163-170.

Morse JM. 1995. Exploring the theoretical basis of nursing using advanced techniques of concept analysis. Advances in Nursing Science 17(3): 31-46.

Morse JM, C Mitcham, JE Hupcey and MC Tason. 1996. Criteria for concept evaluation. Journal of Advanced Nursing 24(2):385-390.

Morse JM, JE Hupcey, C Mitcham and ER Lenz. 1996. Concept analysis in nursing research: a critical appraisal. Research and Theory for Nursing Practice 10 (3):253-277.

Naumanen-Tuomela P. 2001. Finnish occupational health nurses' work and expertise: the clients' perspective. Journal of Advanced Nursing 34 (4):538-544.

Nikkel D. 2014. Unpacking the tacit. Tradition and Discovery: The Polyani Society Periodical 41 (4):32-39.

Nojima Y, T Tomikawa, S Makabe and M Snyder. 2003. Defining characteristics of expertise in Japanese clinical nursing using the Delphi technique. Nursing \& Health Sciences 5 (1):3-11.

Novak JD and AJ Cañas. 2008. The theory underlying concept maps and how to construct and use them. In Technical Report IHMC CmapTools 2006-01 Rev 01-2008, ed Institute for Human and Machine Cognition. 
Florida. http://cmap.ihmc.us/Publications/ResearchPapers/TheoryUnderlyingConceptMaps. pdf (accessed 6 November 2015).

Polanyi M. 1997. The tacit dimension. In L. Pruzak (Ed), Knowledge in organizations:135-146. Boston, MA: Butterworth-Heinemann.

Polanyi M. 2012. Personal knowledge: Towards a post-critical philosophy: Chicago: University of Chicago Press.

Reyes-Galindo LI and TR Duarte. 2015. Bringing tacit knowledge back to contributory and interactional expertise: A reply to Goddiksen. Studies in History and Philosophy of Science 49:99e 102.

Risjord M and M Risjord. 2009. Rethinking concept analysis. Journal of Advanced Nursing 65 (3):684691.

Rodgers BL. 1989. Concepts, analysis, and the development of nursing knowledge: the evolutionary cycle. Journal of Advanced Nursing 14: 330-335.

Rodgers BL and KA Knafl. 2000. Concept development in nursing. Philadelphia, PA: Elsevier.

Rodgers B. 2000a Concept analysis: an evolutionary view. In Concept Development in Nursing:

Foundations, Techniques and Applications. (Eds) B. Rodgers and B. Knapfl. Philadelphia, WB Saunders. 77-102.

Sandelowski M, J Barroso and C Voils. 2007. Using qualitative meta-summary to synthesise qualitative and quantitative descriptive findings. Research in Nursing \& Health 30:99-111.

Sandelowski M. 1994. We are the Stories we Tell Narrative Knowing in Nursing Practice. Journal of Holistic Nursing 12 (1):23-33. 